\title{
Effect of Preparation on Structure and Magnetic Properties of $\mathrm{ZnFe}_{2} \mathrm{O}_{4}$
}

\author{
Mohammad Niyaifar* \\ Department of Physics, Science and Research Branch, Islamic Azad University, Khouzestan, Iran
}

(Received 7 January 2014, Received in final form 20 April 2014, Accepted 14 May 2014)

\begin{abstract}
In this work, Zinc ferrite nanoparticles have been prepared by various methods, conventional (ZC), mechanochemical processing (ZM) and Sol-Gel (ZS) method, to compare their structural and magnetic properties. The cation distribution obtained from XRD shows the degrees of inversions are $4 \%, 14.8 \%$, and $16.4 \%$ from the normal $\mathrm{ZnFe}_{2} \mathrm{O}_{4}$ structure. Fourier transform infrared spectroscopy (FT-IR) confirms changes in cation distribution of $\mathrm{ZnFe}_{2} \mathrm{O}_{4}$ fabricated by sol-gel and mechanochemical processing. The ${ }^{57} \mathrm{Fe}$ Mössbauer spectra of the samples were recorded at room temperature. The spectra exhibit a line broadening. The magnetic properties of the samples were studied by vibration sample magnetometer (VSM) at room temperature and the results show that the sample ZM has ferrimagnetic behaviour.
\end{abstract}

Keywords : zinc ferrite, cation distribution, mossbauer spectroscopy, preparation methods

\section{Introduction}

Investigation of nanoparticle systems has been a subject of continues works in recent years. Recently, progress in synthesis techniques has initiated new surge of concern in ferrites to improve their physical properties and develop their applications [1-3]. Zinc ferrite has long attracted researcher's interests because of its intriguing magnetic properties compared with other spinel ferrites. The bulk $\mathrm{ZnFe}_{2} \mathrm{O}_{4}$ belongs to the normal spinel type with antiferromagnetic properties below the Néel temperature of about $10.5 \mathrm{~K}$ and behaves paramagnetic at room temperature. All the $\mathrm{Zn}^{2+}$ ions reside in the tetrahedral sites (A sites) and the $\mathrm{Fe}^{3+}$ ions are totally in the octahedral sites (B sites). Recently, $\mathrm{ZnFe}_{2} \mathrm{O}_{4}$ nanoparticles prepared by various methods, such as traditional ceramic synthesis, aerogel procedure, low-temperature hydroxide co-precipitation and hydrothermal synthesis, have been studied and observed to be ferrimagnetic or superparamagnetic. The origin of the ferrimagnetic properties of $\mathrm{ZnFe}_{2} \mathrm{O}_{4}$ and other spinel ferrite nanoparticles was studied using lowtemperature Mössbauer spectrometry with applied magnetic field parallel to the direction of gamma rays [4-9]. Large inversion parameters were obtained when the particle size is decreased, and there are spin cantings in

(C)The Korean Magnetics Society. All rights reserved.

*Corresponding author: Tel: +989351055293

Fax:+986114435288, e-mail: md.niyaifar@gmail.com both A and B sites. The main purpose of this study is to compare the obtained experimental information of the zinc ferrite nanoparticles prepared by different methods. Battle et al. [10] compared the ceramic, co-precipitation and hydrothermal methods used to prepare zinc ferrite nanoparticles. In the present work we compare conventional method, sol-gel combustion and mechanochemical methods.

\section{Experimental}

\subsection{Preparation}

\subsubsection{Standard ceramic technique (ZC)}

$\mathrm{ZnO}$ and $\mathrm{Fe}_{2} \mathrm{O}_{3}$, were mixed stoichiometrically, ground to a very fine powder using an agate mortar and then pressed into pellets using an uniaxial press under a pressure of $1.9 \times 108 \mathrm{Nm}^{-2}$. The samples were pre-sintered at $900{ }^{\circ} \mathrm{C}$ with a heating rate of $2^{\circ} \mathrm{C} \min ^{-1}$ for $8 \mathrm{~h}$ and then ground again and pressed into pellets and finally sintered at $1100^{\circ} \mathrm{C}$ in air for $2 \mathrm{~h}$ at the same rate as above.

\subsubsection{Sol-gel auto-combustion (ZS)}

Analytical grade zinc nitrate, iron nitrate and citric acid were used as raw materials to prepare zinc ferrite nanoparticles. The preparation process is described as follows: the molar ratio of $\mathrm{Zn}$ to $\mathrm{Fe}$ was 1:2. First, a certain amount of citric acid was weighed and dissolved in 
diluted water, then $\mathrm{Zn}\left(\mathrm{NO}_{3}\right)_{2} \cdot 6 \mathrm{H}_{2} \mathrm{O}$ and $\mathrm{Fe}\left(\mathrm{NO}_{3}\right)_{3} \cdot 9 \mathrm{H}_{2} \mathrm{O}$ were dissolved in it with a molar ratio of total nitrates to citric acid of 1:1. A small amount of ammonia was added into the solution to adjust the $\mathrm{pH}$ value to about 7 and stabilized the nitrate-citrate sol. During this procedure, the solution was continuously stirred and kept at a temperature of $60^{\circ} \mathrm{C}$. Then, the stabilized nitrate-citrate sol was poured into a tray and heated slowly to $120^{\circ} \mathrm{C}$. The viscosity and color changed as the sol turned into a brown, puffy, porous dry gel. When the temperature was increased to $250^{\circ} \mathrm{C}$, the dried gel simultaneously burnt in a selfpropagating combustion manner until it was completely transformed into loose powder.

\subsubsection{Mechanochemical processing - MCP (ZM)}

The starting materials were AR-grade $\mathrm{ZnO}$ and $\alpha$ $\mathrm{Fe}_{2} \mathrm{O}_{3}$. The powders should be dried at $150{ }^{\circ} \mathrm{C}$ in air for $12 \mathrm{~h}$ prior to use. Dried $\mathrm{ZnO}$ and $\alpha-\mathrm{Fe}_{2} \mathrm{O}_{3}$ were mixed with a molar ratio of $1: 1$ to form the mixture. $30 \mathrm{~g}$ of the mixture, nine stainless steel balls of $2.5 \mathrm{~mm}$ in diameter and forty stainless steel balls of $0.4 \mathrm{~mm}$ in diameter were sealed in a $300 \mathrm{ml}$ stainless steel vial. Mechanochemical milling was performed with a Fritsch P6 type planetary mill for $0-8 \mathrm{~h}$ at $600 \mathrm{rpm}$ using a ball-to-powder mass ratio of $10: 1$. The as milled powder was dried at $100{ }^{\circ} \mathrm{C}$ in air to obtain the nanoparticle precursor. The precursor was subsequently calcined at $600{ }^{\circ} \mathrm{C}$ in air in a porcelain crucible for $1 \mathrm{~h}$ to obtain $\mathrm{ZnFe}_{2} \mathrm{O}_{4}$ nanocrystallites.

\subsection{Characterization}

The crystal structure and average crystallite sizes of the samples were determined by XRD technique on a Seifert diffractometer, using $\mathrm{CuK}_{\alpha}$ radiation in the $2 \theta$ angle range between 20-75. The average crystallite sizes of the samples were determined from the full-width at half-maximum (FWMH) of the strongest reflection, the (311) peak using the Scherrer's formula. Lattice constants and inversion parameters were determined in the standard way based on Rietveld refinements [11]. Room temperature Mössbauer analysis was recorded on a conventional gamma-resonance spectrometer (SM1101) operating in constant-acceleration mode with ${ }^{57} \mathrm{Co}(\mathrm{Rh})$ as the source. Isomer shifts (IS) are

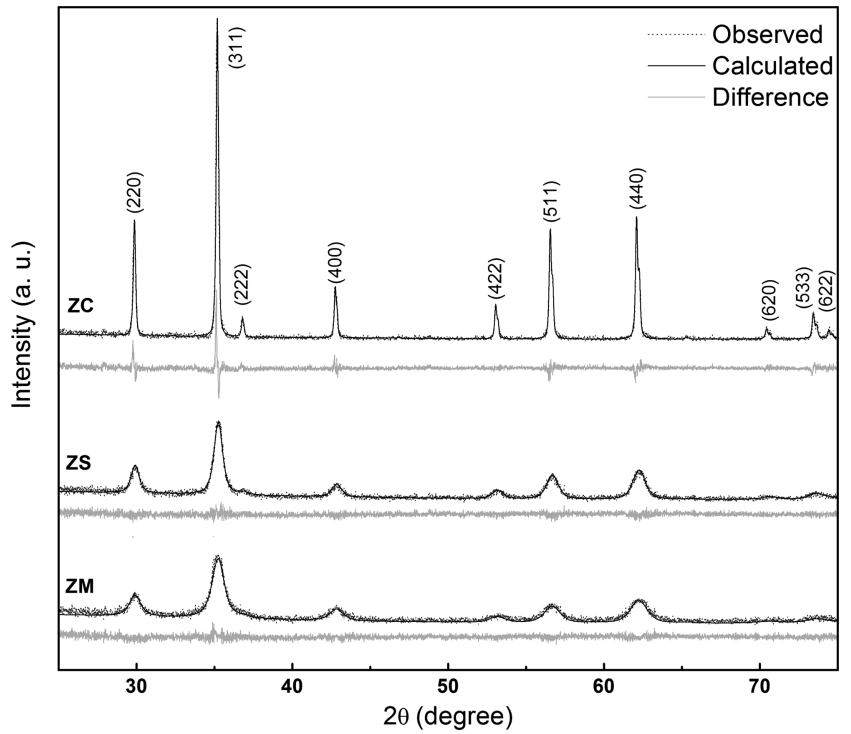

Fig. 1. X-ray diffraction of zinc ferrite samples.

reported relative to $\alpha$-Fe at room temperature. The spectra were computer analyzed using the standard program. Magnetic characterizations were carried out using a vibrating sample magnetometer at a maximum field 8 kOe at $300 \mathrm{~K}$.

\section{Results and Discussion}

\subsection{Structural analysis}

Fig. 1 shows the XRD patterns of the samples prepared in this work. All diffraction peaks can be indexed in a face centered cubic lattice and the position along with relative intensity of the peaks match with standard zinc ferrite phase (JCPDS 22-1012). As it is clear from inspection of diffraction patterns, the peaks of ZM sample are broader than ZS and ZC samples. We used Scherrer's formula to obtain average crystallite sizes that are shown in Table 1. The structural analysis, cation distribution and lattice parameter calculations of the samples are carried out by Rietveld refinements. The cation occupancies together with the lattice constants of the samples are given in Table 1. The dots in Fig. 1 represent the experimental spectrum and the continuous curves are related to the

Table 1. Lattice constant, particle size and Mössbauer parameters for zinc ferrite samples.

\begin{tabular}{|c|c|c|c|c|c|c|c|}
\hline \multirow{2}{*}{$\begin{array}{l}\text { Methods of } \\
\text { preparation }\end{array}$} & \multirow{2}{*}{$\begin{array}{l}\text { The Inversion } \\
\text { parameter }(\mathrm{X})\end{array}$} & \multirow{2}{*}{$\frac{\text { Cation Distribution }}{\left(\mathrm{Zn}_{1-\mathrm{x}} \mathrm{Fe}_{\mathrm{x}}\right)_{\mathrm{tet}}\left[\mathrm{Zn}_{\mathrm{x}} \mathrm{Fe}_{2-\mathrm{x}}\right]_{\text {oct }} \mathrm{O}_{4}}$} & \multirow[b]{2}{*}{ GOF } & \multirow[b]{2}{*}{$\mathrm{D}(\mathrm{nm})$} & \multirow{2}{*}{$\begin{array}{c}\mathrm{a} \\
(\mathrm{nm})\end{array}$} & \multicolumn{2}{|c|}{ Mossbauer parameters } \\
\hline & & & & & & $\begin{array}{c}\text { QS } \\
(\mathrm{mm} / \mathrm{s})\end{array}$ & $\begin{array}{c}\text { IS } \\
(\mathrm{mm} / \mathrm{s})\end{array}$ \\
\hline $\mathrm{ZC}$ & 0.040 & $\left(\mathrm{Zn}_{0.96} \mathrm{Fe}_{0.04}\right)_{\mathrm{tet}}\left[\mathrm{Zn}_{0.04} \mathrm{Fe}_{1.96}\right]_{\text {oct }}$ & 1.21 & 110 & 0.8452 & 0.38 & 0.32 \\
\hline $\mathrm{ZS}$ & 0.148 & $\left(\mathrm{Zn}_{0.852} \mathrm{Fe}_{0.148}\right)_{\mathrm{tet}}\left[\mathrm{Zn}_{0.148} \mathrm{Fe}_{1.852}\right]_{\mathrm{oct}}$ & 1.08 & 20 & 0.8445 & 0.41 & 0.32 \\
\hline $\mathrm{ZM}$ & 0.164 & $\left(\mathrm{Zn}_{0.836} \mathrm{Fe}_{0.164}\right)_{\mathrm{tet}}\left[\mathrm{Zn}_{0.164} \mathrm{Fe}_{1.836}\right]_{\text {oct }}$ & 1.07 & 15 & 0.8441 & 0.44 & 0.32 \\
\hline
\end{tabular}




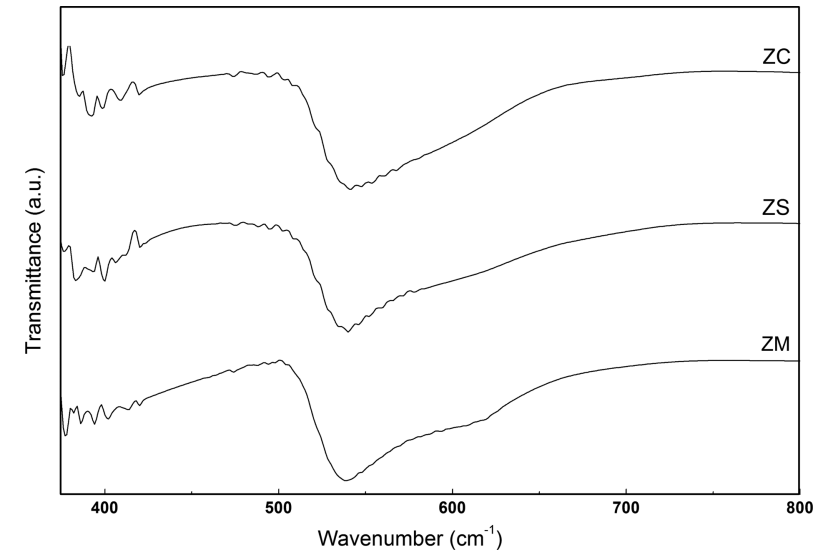

Fig. 2. FT-IR of zinc ferrite samples.

fitting of the experimental data. The cation distribution of samples ZS and ZM show a transition from normal spinel to mixed spinel as the particle size of samples are decreased. This cation redistribution could be due to correlation between particle size and ligand field. The decrease in particle size causes a reduction in ligand field strength which leads to cation redistribution. The lattice constant for samples ZM and ZS has been decreased compare to that of the sample ZC. It is known that the redistribution of cations between (A) and [B] sites drastically affects lattice constant of the spinel structure. Also changes of unit cell dimensions lead to alteration in the $\mathrm{Fe}^{3+}-\mathrm{O}^{2-}$ $\mathrm{Fe}^{3+}$ bond angle [12]. These phenomena may be the cause of the cation redistribution of samples $\mathrm{ZM}$ and $\mathrm{ZS}$ compare to that of sample ZC.

Fig. 2 shows the FT-IR spectra of the samples. With respect to ferrite structure the most prominent part of IR is in the $800-250 \mathrm{~cm}^{-1}$ range [13]. This range is assigned to vibration of metal-oxygen bands in octahedral and tetrahedral sites. However, in our spectra only stretching vibration in tetrahedral site can be observed. A slight shift for the tetrahedral absorption peak towards the higher wavenumber for samples ZS and ZM compare to that of sample ZC can be seen. These shifts indicate the changes of the metal-oxygen bonds and the effect of atomic weight due to the transition from normal to mixed spinel structure [14]. This has happened by the decrease of the zinc ion (and, in turn, by the increase of the iron ion) in tetrahedral site and is in agreement with the XRD refinement results.

\subsection{Mössbauer analysis}

The ${ }^{57} \mathrm{Fe}$ Mössbauer spectra of the samples were recorded at room temperature (Fig. 3). The dots in this figure present the experimental spectrum and the continuous curves are related to the least squares fitting of the experi-

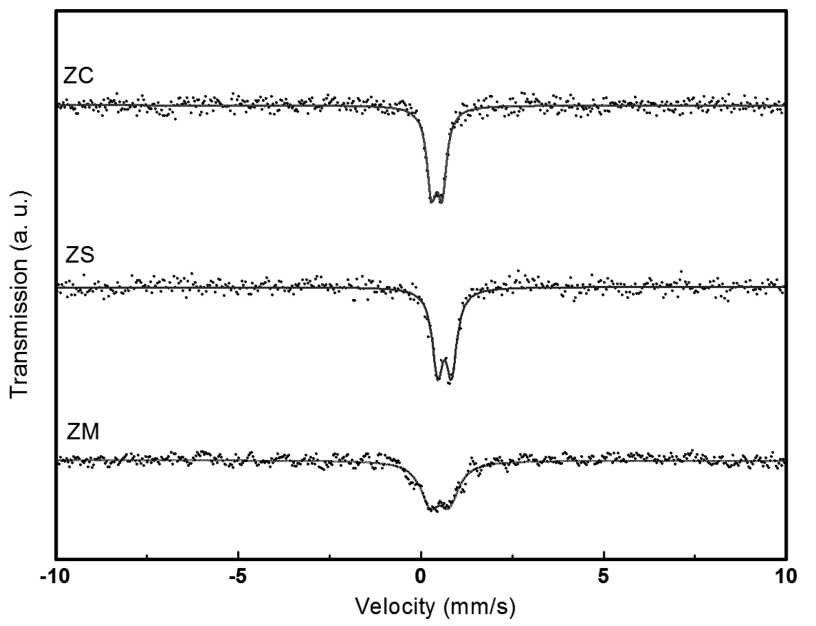

Fig. 3. Mössbauer spectra of zinc ferrite samples at room temperature.

mental data. Table 1 summarizes the various Mössbauer refined parameters. The Mössbauer spectrums of all the samples are fitted with one doublet. This is due to either paramagnetic or superparamagnetic characters of zinc ferrite system which discussed in previous works $[15,16]$. It is obvious from Table 1 that the isomer shift values are the same for all the samples. The isomer shift is characteristic of $\mathrm{Fe}^{+3}$ charge state and this shows that the selectron density at the Mössbauer active nuclear site is not so much affected by the methods of fabrication. The quadrupole splitting values of ZM and ZS are slightly more than that of $Z C$. The increase in quadrupole splitting of ZM and ZS can be due to two sources; the crystalline bonds in surface atoms are not complete i.e. reduction of particle size causes an increase in the iron ions sitting at or near the surface. Therefore, iron ions will find themselves in a more asymmetric environment and hence will show larger QS. In another hand, as shown by XRD refinement, the cation distribution has changed so distribution of iron ions in octahedral and tetrahedral sites could change charge distribution around the iron ions and causes an increase in QS.

In agreement with previous studies $[17,18]$ we observed that the absorption area increases for ZM and ZS compare to that of ZC. It is well known that area of the curve is a measure of recoil free fraction. This is expected as the particles size decreases the Mössbauer nuclides sitting at the surface are not bounded so strongly and hence causing a decrease in recoil free fraction [19-21]. Therefore the area under curve is small for ZM and ZS compare to that of ZC. The observed line broadening in the samples ZM and ZS is attributed to an increase in fraction of disordered interfacial regions as grain size decreases and the 


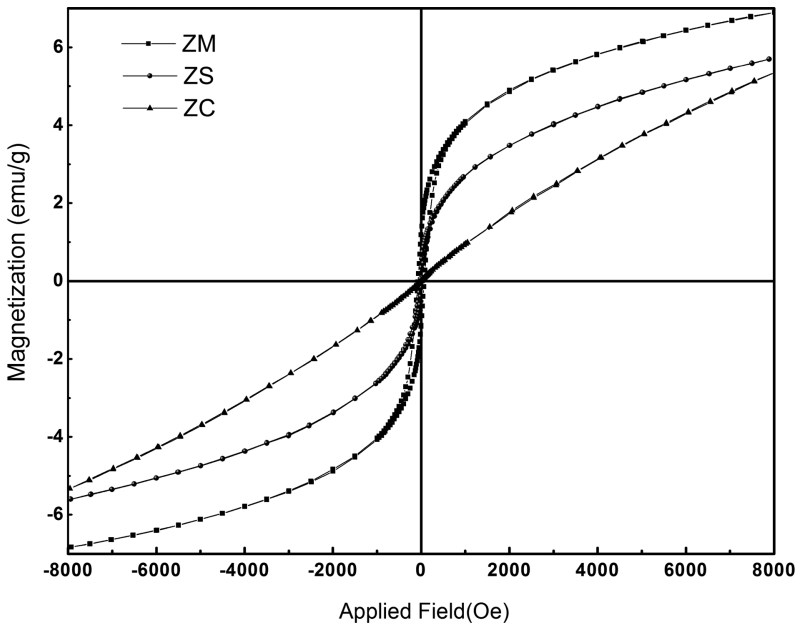

Fig. 4. Magnetization curves of zinc ferrite samples at room temperature.

site distributions of zinc and iron ions are changed.

\subsection{Magnetic Properties}

Fig. 4, shows the $\mathrm{M}-\mathrm{H}$ curves of all prepared zinc ferrite samples at room temperature. The magnetization curve for the sample $\mathrm{ZC}$ is a straight line with a positive slope passing through the origin. So the paramagnetic behavior of the sample confirms the formation of a normal spinel structure. The magnetization curves for the samples $\mathrm{ZM}$ and ZS exhibit a typical $\mathrm{S}$ type shape, and their coercivities are very small. The hysteresis loops of the samples could not be saturated with the available maximum field $(8 \mathrm{kOe})$. The shapes of the M-B curves show that the $\mathrm{ZM}$ and $\mathrm{ZS}$ samples have some amount of inversion which is confirmed by XRD refinements. Hence, some percentage of $\mathrm{Fe}^{+3}$ ions occupies the tetrahedral site which switches on A-B superexchange interaction and causes an increase in magnetization. The large value of the magnetization observed for the ZM sample compare to that of the sample ZS is attributed to larger degree of inversion factor.

\section{Conclusions}

Single-phase zinc ferrite nanoparticles have been prepared by different methods. The degree of inversion of $\mathrm{ZnFe}_{2} \mathrm{O}_{4}$ prepared by ceramic route was determined to be $96 \%$ normal. However, this value was reduced to $85.2 \%$ for $\mathrm{ZnFe}_{2} \mathrm{O}_{4}$ prepared by sol-gel method and $83.6 \%$ for that prepared via mechanochemical. The shifts in FT-IR spectra indicating the changes of the metal-oxygen bonds and the effect of atomic weight due to the transition from normal to mixed spinel structure. The observed line broad- ening in Mossbauer spectra is attributed to presence of $\mathrm{Fe}^{3+}$ at both octahedral and tetrahedral sites, and also increment of interfacial disordered regions in nanoparticles samples due to size reduction. From VSM results, the samples show completely different hysteresis behaviours and therefore different strengths of exchange interactions which the main cause is from different fabrication method.

\section{Acknowledgments}

The authors acknowledges supported from Science and Research Branch, Islamic Azad University through Grant No. 52323900701003.

\section{References}

[1] H. Hamdeh, J. C. Ho, S. A. Oliver, R. J. Willey, G. Oliveri, and G. Busca, J. Appl. Phys. 81, 1851 (1997).

[2] S. K. Gangwal, J. M. Stogner, S. M. Harkins, and S. J. Bossart, Env. Progr. 8, 26 (1989).

[3] V. Šepelák, K. Jancke, J. Richter-Mendau, U. Steinike, D.Chr. Uecker, and A.Yu. Rogachev, Kona, 12, 87 (1994).

[4] S. A. Morrison, C. L. Cahill, E. E. Carpenter, S. Calvin, R. Swaminathan, M. E. McHenry, and V. G. Harris, J. Appl. Phys. 95, 6392 (2004).

[5] S. A. Oliver, V. G. Harris, H. H. Hamdeh, and J. C. Ho, Appl. Phys. Lett. 76, 2761 (2000).

[6] N. Ponpandian, A. Narayanasamy, C. N. Chinnasamy, N. Sivakumar, J. M. Greneche, K. Chattopadhyay, K. Shinoda, B. Jeyadevan, and K. Tohji, Appl. Phys. Lett. 86, 192510 (2005).

[7] S. A. Oliver, H. H. Hamdeh, and J. C. Ho, Phys. Rev. B 60, 3400 (1999).

[8] C. N. Chinnasamy, A. Narayanasamy, N. Ponpandian, K. Chattopadhyay, H. Guerault, and J.-M. Greneche, J. Phys., Condens. Matter. 12, 7795 (2000).

[9] H. H. Hamdeh, J. C. Ho, S. A. Oliver, R. J. Willey, G. Oliveri, and G. Busca, J. Appl. Phys. 81, 1851 (1997).

[10] J. Battle, T. Clark, and B. J. Evans, J. Phys. IV France 07, C1-257 (1997).

[11] B. D. Cullity and S. R. Stock, Element of X-Ray Diffraction, Prentice Hall, New Jersey (2001).

[12] V. Šepelák, L. Widle, U. Steinike, and K. D. Becker, Mater. Sci. Eng. A 375, 865 (2004).

[13] R. D. Waldron, Phys. Rev. 99, 1727 (1955).

[14] M. Reichenbächer and J. Popp, Challenges in molecular structure determination, Springer-Verlag, Berlin Heidelberg (2012).

[15] Y. Ahn, E. J. Choi, and S. Kim, J. Korean Phys. Soc. 41, 123 (2002).

[16] C. Upadhyay and H. C. Verma, Appl. Phys. Lett. 85, 2074 (2004).

[17] J. P. Singh, R. C. Srivastava, H. M. Agrawal, and R. P. S. Kushwaha, J. Hyper. Inter. 183, 221 (2008). 
[18] M. K. Roy, B. Halder, and H. C. Verma, Nanotechnology 17, 232 (2006).

[19] P. Druska, U. Steinke, and V. Šepelák, J. Soild. State. Chem. 146, 13 (1999).
[20] C. N. Chinnasamy, A. Narayanasamy, N. Ponpandian, and K. Chattopadhyay, Mater. Sci. Eng. A 304, 983 (2001).

[21] H. Ehrhardt, S. J. Campbell, and M. Hofmann, J. Alloys Compd. 339, 255 (2002). 